\title{
Corporate Blogging: The New Age PR Tool
}

\author{
Leena Philip
}

CMS

\begin{abstract}
Effective public relations can create and build up the image of an individual or an organisation or a nation. At the time of adverse publicity or when the organisation is under crisis an effective Public Relations can remove the "misunderstanding" and can create mutual understanding between the organisation and the public. Public relations, in the internal environment area, are directed to both the entire organization and to its individual departments and units. Internal communication and good internal communication channels are of paramount importance. From an internal perspective, organizations must be able to communicate effectively with its human resources in order to streamline organizational development. Finally, public relations must also be an important part of internal communication to promote planned change and development within the organization.
\end{abstract}

Keywords: Corporate Blogging: The New Age PR Tool

\section{Introduction}

In the past several years, a number of trends have emerged in the PR industry, with no sign of disappearing anytime soon. The biggest factor related to these new trends is social media. The rise of everything from Facebook, Twitter, and Linkedln to Instagram, Snapchat, and Vine has changed the way public relations teams operate in a number of ways. These networks give consumers the opportunity to speak directly to a brand or a client; PR professionals used to be able to dictate what information was being released and when, but conversations are a two-way street now. A much wider audience for a PR team means it's not just about journalists anymore - bloggers are the new influencers. PR practitioners used to really focus on having good relationships with big media, but now the media target has grown. There are bloggers and YouTube personalities with millions of followers that organisations need to develop relationships with now. Today, a good relationship with a key influencer can bring a wealth of publicity to a brand.

Until recently most public relations activity involved person-to-person contact between PR professionals and members of the media, such as journalists and television news reporters. However, several trends are developing that alter the tasks performed by PR people. In most cases these changes are the result of new Internet technologies that are quickly gaining widespread acceptance among Internet users and are becoming new media outlets in their own right. The new trends include:

\section{- Updating Corporate News}

- Corporate Blogs: Many companies in high-tech fields, such as eBay, Google, and Microsoft, and traditionally low-tech fields, such as General Motors, McDonalds, and Wells Fargo Bank, now produce in-house blogs that report on happenings at the company. These blogs enable company employees, including CEOs and marketers, to post messages updating company developments and, consequently, serve as a useful PR tool.

- Social Media by far the most significant trend to affect public relations in the last 25 years is the impact played by social media. In a matter of just a few years, social networks, including Facebook, Twitter, and Linkedln, have created opportunities for monitoring and communicating that are quickly raising these methods to the top of the list of PR tools.

Many organizations that start using content marketing or social media marketing, and want to offer content in a more conversational and personal way, start their efforts with a blog. Although corporate blogging is far from new and lots of companies have a blog, several others don't. 
The social media and content marketing activities of many companies in reality are limited to driving interactions and conversions via blogs and the social platforms connected with them. Such social media and content marketing programs often are limited to publishing, listening, responding and acting with a central role for content, as shared via blogs. Although social media and content marketing offer much more possibilities than blogging, the focus on content and blogs is natural. The majority of traffic to websites and of online generated leads comes from search engines. This is because search engines still are a predominant source for buyers during various stages of their buyer journey. Furthermore, blogs also get more consulted as people actively look for information during their buying journey and increasingly become social-savvy.

\section{Review of literature}

2.1 Blogging- a powerful public relation marketing tool by Minal Kashyap and Kamal Katiya is a study based on the latest innovation currently having an impact on Public Relation is blog. The research goes on to studying the popularity of blogs, where it is explained that search engine prefers blogs, blogs can establish credibility for a business, others may include blogs as a medium of instant communication, also people enjoy fresh, interesting and relevant content and the main motive that blogs also attract media attention.

Variations in this study are created by building a relation between the individual's age and frequency of blogging. Secondly, another relation between the individual's gender and visits to type of blogs. This is graphed as the Hypothesis Testing. Visitors subscribe to a blog's feeds in order to stay up to date with content that being posted on subjects that interests them. Some blogs are such that which indirectly influences the mind of consumer's towards buying the product. It is also been evaluated that there is a relationship between age of an individual and frequency of visiting the blogs, similarly there is a relation between gender and influence towards the type of blog. Various companies use blogging as a tool to market their products and services which in turn builds goodwill amongst blog followers. Blogs provide a unique and personal way to communicate with current and prospective customers. By talking to people, in a conversational manner, a blog puts a human face on a company that is difficult to duplicate in any other way. Perhaps the single most powerful aspects of blogs, in the area of public relations, is the personalization aspect.

2.2 Critical Analysis of blogging in Public by Philip Joseph is a research paper conducts an analysis of blogs as a public relation tool. Following an overview of blogs, attention is given to how blogs can be used more effectively by public relation professionals and how blogs are favoured by communication firms and consultants as essential Public Relation tool. The research concludes the strengths and weakness of blogs as public relation tools, describe their value as research and framing tools, and provide some data about how they are used. Also, using blogs as a way to influence individuals and publics is one of the most frequently mentioned characteristics of blogs by public relation professionals. Allowing or encouraging visitors to an organization Web site to participate in how online news and information is framed is possibly the greatest strength of blogs and feature of the most important to public relation professionals. Many people nowadays have begun to mistrust the traditional way of public relations approach as they lack honesty. The openness of a blog changes that perception entirely. A blog can enhance that perception of honesty by delivering the straight goods on an issue. With that open approach, lacking the traditional tightly controlled message, trust in the company is enhanced in both the short and longer terms, which trust translates into more lifelong customers and clients.

2.3 How Blogging changed the PR Game by Brent Gleeson is an article where we get to learn more about blogging and its credibility as Blogging has become a part of daily lives. There are millions of blogs available to readers, and two out of three people read blogs multiple times a week. It's not just a hobby anymore, many influencers have made blogging their fulltime job and dedicate their efforts to cultivating a large, loyal following. Even those who blog casually still develop an audience and have move forward in the digital sphere. This article concludes by stating that bloggers have established a key role in today's consumer behaviour and digital marketing strategies. Brands and marketers that adapt to this changing landscape will be able to positively leverage this reality and boost their brand awareness online. In the time of crisis or disaster, a blog can provide a rapid response and update system, to get out an unfiltered message to the reading audience. The journalists can keep up with developments and write stories based on the postings. The company gains untold additional credibility with the general public due to the policy of the open communications channels. Businesses seeking a public relation vehicle, that provides numerous additional benefits, should consider adding a blog component to their website. The authentic and personalized blog voice is a natural fit for any public relations effort. A rapid growing number of journalists and editors are reading blogs on a daily basis. It is becoming imperative that a company start to blog to keep up with that trend. 
2.4 Corporate Blogs as a Public Relation Tool by Brett Harrison is a study analysed current practice and strategies of corporate blogs as a public relations tool. Applying the relational maintenance framework, a content analysis was conducted to examine how major corporations utilize blogs for building and maintaining their relationships with various publics. The research looks at what are Corporate Blogs and the key characteristics and strategies applied in corporate blogs. A corporate blog is a unique form of blogs that has been explored by public relation practitioners. Also described as 'a hybrid of the personal blog'. These blogs are fairly new and feature the insights, assessments, commentary and other discourse devoted to a single company. Corporate blogs can be defined as a blog that is endorsed explicitly or implicitly by a company and posted by a person (or a group of people) who are affiliated with the company. The key strategies for maintain a twoway symmetrical public relationship is:

- Here, the first strategy would be "Access" and is defined as providing public access to representatives of organisation or organisational decision making process and at the same time providing public relation practitioners with access to members of publics. This strategy is compared to the two-way symmetric communication model.

- Secondly, it would be 'Positivity' that refers to interacting with each other in a cheerful way and attempting to make interactions enjoyable.

- Third is 'Openness' referred to self-disclosure and free conversations between partners in a relationship.

- Fourth being 'Assurance' is showing ones continuation in the relationship and commitment to the partner and the relationship. This is also the attempts made by parties in the relationship to assure the other parties that they and their concerns are legitimate.

- Fifth is 'Social Networks' refers to interacting with or relying on common affiliations and spending time with common friends.

- Finally, 'Sharing Tasks' is defined as attempts to maintain a relationship by performing one's shared responsibilities. In an interpersonal context, relationships can flourish when both parties involved in a relationship feel that the other is investing his/her time in taking shared responsibilities.

This study concludes by stating that while corporate blogs tend to adopt various relational maintenance strategies to maintain good relationships with their visitors, application of such strategies are rarely used. For public relations practitioners exploring the blogosphere for a potentially effective new communication tool, this study also present a new approach for examining corporate blogs as a public relations tool by applying relational maintenance strategies.

2.5 Blogs and Business Opportunities and Headaches by Wallace Wood, Robert Behling and Susan Haugen is a study based on Blogging that has become a significant part of online culture. Blogging is transforming the way the Internet is being used by allowing individuals and business to communicate directly with other individuals, employees and customers while encouraging an exchange of ideas. The study shows how blogging is gaining momentum and will be used by more and more companies and organizations. Businesses are aware that blogging is a very inexpensive way to help them gain Internet and market presence, obtain customers feedback and provide a forum for employees to share ideas. While blogs have their disadvantages, they also hold great potential for organizations. Creating an outlet for public discussion can enhance the reputation of the organization and provide a timely means for customers to interact with the company in a informal way and put a human face on company communication.

2.6 Why is PR Agencies Blogging? An Exploratory study of the blogging practices of public Relation Agencies by Rihanna Fursdon and Melanie James. Is a study on Blogging a form of social media and is one of the fastest growing areas of communication in public relations practice? It has been argued that blogging is breaking down the barriers to communication, enabling more equal and democratic dialogue between individuals, groups and organisations. A number of researchers have investigated the use of blogs by organisation. There have been suggestions that the extent to which blogs are interactive, interlinked and oriented towards large-scale events is exaggerated by blog writers, including journalists and academics. This exploratory project was seen as initial step in reducing the disparity between practitioner and academic perspectives of blogging practice in public relations with a view to better understanding and enhancing practice and theory development in this area. There were several findings in this analysis, five out of the six practitioners indicated that the main purpose of the blog was to raise their agency's profile and to promote their agency. The six practitioners observed that the industry was moving increasingly online, and all indicated that they felt the need to have a 
blog in order to establish or maintain an online presence. This research was concluded by indicating that the practitioners in this study use blogs in what could be described as a combination of both co-creational and functional approaches. Perhaps future work in the field will find that agency blogging centres on finding the right balance between internal and external interests. There are a number of emergent research areas for blog use by PR practitioners and it is noted that there are a number of researchers already producing annual investigations into this area of practice. However, this exploratory study does point to some areas that future researchers may like to consider, such as: widening the current research focus area to include functional as well as co-creational perspectives of practice or looking for evidence of other theoretical perspectives emerging from the research data.

2.7 Role of Corporate Blogs in Branding by Dushyant Pratap Singh Chauhan is an article based on corporate blogging is a new form of online communication that is being used by companies as a PR tool. Today customers are moving away from the traditional media and so the need to be visible in the consumer's eye, new media is essential. In India corporate blogging is a relatively new phenomenon although it began way back in 2007. The study attempts to explore how corporate blogging is a new communication tool for companies. It tries to determine recent trends in corporate blogging especially in India and to find out what is the future of corporate blogging. The researcher has used the case study method. The study will be significant in presenting the Indian perspective towards corporate blogging. Corporate blogging is a new form of online communication that is being used by companies as a PR tool. Today customers are moving away from the traditional media and so the need to be visible in the consumer's eye, new media is essential. Kamla Bhatt in her article "A Different Blogosphere in India", for the Financial Express says that there is an increasing realisation that corporate blogging can help bridge the gap between companies and their stakeholders like their employees, customers or investors. She quotes Rajesh Lalwani of Blog works who points out, "Corporate blogging allows a faceless entity to become real and allows companies to build trust through transparent conversations." Talking about the corporate blogging scene in India she says that Indian companies have barely scratched the surface and discovered the value created through corporate blogs. "It is early days yet and the large corporate are yet to adopt them in a big way, but it has been adopted by entrepreneurs on the other hand," says Lalwani. She also quotes Kiruba Shankar, who helps clients with their blogging needs. He says, "Corporate blogging is still in its infancy in India. Whenever I speak with heads of corporations, they say that blogging is important but very few actually turn those words to action." This study concludes by stating that the final objective was to identify the future of corporate blogging. Numerous studies have pointed towards the fact that the new media is here to stay. Corporate blogging is expected to remain an important Social Media tool, or even grow in popularity over the years. It has been identified to be the essential backbone of every company's Social Media strategy, as it allows companies to establish a content hub where complex topics can be discussed in-depth, without any interference of the traditional media. Companies connect with the customers through blogs. The study has found out that corporate blogging as a trend has to still develop in India. There are only a handful of Indian companies that have proper blogs. The companies need to realize that blogs are not mere sender oriented platforms. They can be interactive too. There has to be more awareness about the real value of corporate blogging in India.

\section{Research design}

\subsection{Title}

"Corporate blogging: The new age PR tool"

\subsection{Problem Statement}

Defining the research problem is important as it helps one solve the problem. Researcher was basically keen in analysing blogging as a tool used by PR professionals' nowadays. Researcher chooses a study on 'Blogging: The new Public Relations tool', in order to assess the impact and importance of blogs.

For any company or organisation, marketing and building a relation with clients and other organisations around it is very essential, this is where a PR professionals comes in action. He /she bridge the gap between a company and its publics. Through this study we come to know the importance and impact of blogging for public relation professionals.

\subsection{Objectives of the study}

- To asses blogging and its importance 
- To identify whether PR professionals use blogs

- To identify the reach and impact of blogs

- To understand blogs as public relations tool

- To understand whether PR and blogging go hand in hand

- To find out how blogging is a new communication tool for companies.

\subsection{Scope of the study}

- This study is helpful for further researches based on public relations and blogging

- It is helpful in understanding blogs on a PR perspective

\subsection{Sample Size}

The researcher interviewed four resource people. These people were from the PR and Communications industry possessing above four years of experience and used blogging as a strong tool for communication. They are

1.Prateek Thakker, Senior Account Executive: MSLGROUP

2. Pravin Shiriyannavar, Public Relation Executive: BRAND-COMM

3. Suman Prasad, Senior Management Supervisor: HILL+KNOWLTON STRATEGIES

4. Rahul Gemawath, Journalist and Digital Marketer: GOODTIME NATION

\subsection{Ways of selecting sample size}

- Experience- For instance, incorporates those things promptly accessible or advantageous to gather. A decision of little specimen sizes, however at times important, can bring about wide certainty interims or dangers of blunders in factual theory testing.

\section{Data analysis and findings}

\subsection{In Depth-Interviews}

\subsubsection{Interview 1}

In an interview with Pravin Shiriyannavar, threw light on the benefits of "Blogging: The new Public Relation tool." Pravin is a public relation professional working at Brand-Comm and having an experience spanning of more than 5 years. He answered to the following questionnaire starting with talking how public relation is a profession that looks after the reputation of a personality or a company. Public relations specialists work with the aim of helping the company and its customers earn mutual understanding. PR is a planned and continuous effort of establishing and maintaining goodwill of any organization or person. This job is created to provide positive publicity to a company's clients and enhance its reputation. A perfect PR must have the knowledge of some important factors such as persuasion, information, communication, public opinion and public policies.

In the interview Pravin admitted using Blogs as a communication tool and also blogging helps in shaping the brand value of his organisation. He said that a blog can enhance that perception of honesty by delivering the straight goods on an issue. With that open approach, lacking the traditional tightly controlled message, trust in the company is enhanced in both the short and longer terms, which trust translates into more lifelong customers and clients. He also added saying that by writing about your industry, reviewing products, providing company news, and commenting on various business and economics issues, your blog is a ready source of news stories.

He also revealed about how this tool function in the PR process. By posting regular and open information on your company blog, you can address the crisis, fairly and honestly. Keeping the public completely aware of where you're business stands, and what is the plan going forward, helps to improve confidence from your readership. Blogs provide an unlimited number of postings per day. You can update what is happening, during the peak of the crisis, in real time. 
Blog followers' evaluation on the believability of information posted on blog sites has significant impact on changes in their opinions/viewpoints. The more a participant believes the information to be reliable, fair, and trustworthy, the higher the likelihood that they will change their opinion to fit what they read on blog sites.Participants have strong tendency to continue read blogging. They have positive attitude toward blogging. They think blogging is entertaining, interesting, good, and fun .They think blogging is useful as a social networking tool to improve their relationships with others.

Pravin also spoke about the future of blogging and said that it would sustain for a long period of time. Blogging will never be dead. But transformation of blogging will happen, and we should be prepared for that. This is true that competition is tough now compare to the earlier days of blogging. Now every day millions of articles are posted and thousands of blog created. So it's now more important to provide unique, in-depth and quality content.

You should develop a different rapport with each reporter so that you can account for their various interests, motivations, styles, and personalities. Some reporters might need more prodding than others. You might need to watch out for reporters known for misleading and spinning stories. As for contacting them, social media skills may come in handy in addition to the more traditional routes like email and phone calls.

\subsubsection{Interview 2}

In an interview with Prateek Thakker, throwing light on the benefits of "Blogging: The new Public Relations tool." Prateek is a public relation practitioner since 3 years and also started blogging a while back. He answered to the following questionnaire sharing his experiences of working as PR practitioner and also how writing blogs helped him to assess his work and experience. He said that sometimes public relation is an effort to influence the public. This is especially true for political action groups, associations and other groups. Sometimes public relation is community relations, just look around your own community to see how many companies and organizations have a community affairs initiative or a person in charge with a related title. In larger, publicly held firms, this person is sometimes the director of investor relations. Investors are a public entity, so in this case public relation is appropriate.

Prateek added on saying what the public wants to hear is a good story. Good PR is the telling of a good story, the better the story, the better the acceptance by the public and the better the public relations. Of course if the story is especially appealing to those that could be your clients, then you could have a PR homerun. In this case, it is communication with your target market that may or may not be very public. He started blogging recently and had to say that there is no denying that the cultural phenomenon that is blogging has a big impact on the world. Indeed, many news stories, memes, and artistic efforts either air their head via this medium, or are exposed to the wider world by it. Although WikiLeaks is the organisation that has hit headlines recently for exposure of information, blogs over the years have had at least an equal, if not greater, impact, although perhaps not quite on such a global scale.

$\mathrm{He}$ also added on taking about blogs as a cultural perspective, it's a brilliant way for amateur artists to bring their work to the wider world, especially seeing as they are long past the golden era of MySpace furthermore, although MySpace had more of an ease of surfing through pages one might be interested in, the possibility of stumbling across something potentially life changing is almost infinitesimal when compared to surfing blogs, simply due to the greater scope for artistic license offered by the culture of the blog.

Prateek also spoke added his obligations with the audience, while a blogger doesn't have to communicate with public relations professionals at all, there's a pretty good chance they write about the industry or even the company that the PR pro represents from time to time. At some point, the blogger may need information about the company or a product they can't find online, a logo or company image to use with a piece they've written, a quote or reaction from the company to some piece of news or a clarification or explanation of something the company does. Public relations professionals are the appropriate contacts for inquiries. Not communicating with the PR folks at all could limit your ability to serve your audience with accurate information. Furthermore, sometimes the pitch or the press release is about some news or a new product that the blogger's audience should know about. By ignoring pitches, or demanding paid media treatment of said information, a blogger is doing a disservice to his or her audience as that limits or adulterates the information the audience is given.

The only way to make sure that your translation business is running properly and to gain the respect you are owed is by showing that you're a professional and reliable business partner who adds value to the clients' business. Thus you deserve proper compensation, proper feedback and proper payments. Blogging is passion. If you are passionate then there is lots of future. First think yourself, do you have passion on this. He concluded saying "before I go on for too long, although 
blogging certainly has its downsides, which sensationalists would call infecting people with stupidity, rudeness and antisocial behaviour its upsides, as outlined above, outweigh them. Blogging has changed the world, and brought information more freely than any statutory input ever could."

\subsubsection{Interview 3}

In an interview with Suman Prasad, shared a few experiences about "Blogging: The new Public Relations tool". Suman is a blogger and also a PR practitioner for his organisation. His PR tools include attending public events, press releases, newsletters, social media marketing and blogging.

In order to attract public attention and keep it engaged with a particular organisation or an individual, PR specialists take an advantage of every public event and the opportunity to speak publicly. This enables them to directly reach the public attending the event and indirectly, a much larger audience. Sending newsletters, relevant information about the organisation and its products or services directly to the target audience is also a common method to create and maintain a strong relationship with the public. Newsletters offering promotional products are also a common marketing strategy but PR specialists use it to share news and general information that may be of interest to the target audience rather than merely promoting products or services.

On blogging he said that to reach the online audience, PR specialists use the digital forms of press releases and newsletters but they also use a variety of other tools such as blogging and recently, micro blogging. It allows them to create and maintain a relationship with the target audience as well as establish a two-way communication.

He also detailed the simple reasons of writing blogs that you don't need technical expertise to write a blog. You add pages or articles through a Windows type of interface so there is no need for a web designer to update it for you can do it all yourself and in double quick time. Also, your readers can respond to your posts so that you can start to see who is interested in the same areas as you or as a business open a conversation with potential clients, suppliers or partners. The perfect opener to developing a relationship and a network. He also spoke about search engine magnets, with regular posts, categorised content and search engine friendly links and addresses, business blogs become ideal places for Search Engines to find the type of content they love and you can rank very highly.A blog is an excellent tool to help to share information easily within your company, manage projects, develop teams and hugely improve the internal communications. He also added when you regularly produce useful and relevant content on your blog, you'll be seen as a thought leader. You make yourself more relevant when you publish evergreen content on your blog. Your blog will be a helpful resource to your existing and prospective customers, and it will improve their customer service experience.

He concluded saying that blogging is going to remain here for a long long time. Its nature may keep changing and it might be supplanted with a form of blogging that is given another name, but the essential part of it remains, people expressing themselves on the web in long form, in the form of posts that are updated regularly.

\subsubsection{Interview 4}

In an interview with Rahul, working as a blogger for GoodTime Nation. He is been writing blogs since a while now and is well known and has a good amount of followers. Rahul has also worked with public relation organisations and companies. He shared his experience on blogging saying that maintaining a blog is not an easy task. Everything is based efforts have successes, but for this, it is necessary to have platforms and tools such as Word Press SEO plugins, to perform this task. However, blogs need for a presence on social networks such as Facebook, Google+, Twitter, among others. Without a presence in social networks, it is impossible to interact with people, which is essential in the world of marketing and SEO.

He also pointed out the key features blogs must have the blogging platform should be mobile friendly. It should be updated to the latest technology, it shouldn't be rigid.It should also be user friendly. The control panel should be easy understandable, must have well-structured layout, text and html ratio should be good. It must be hacking proof also shouldn't require much coding knowledge. Easy diagnose and error rectification. Easy to manage, low maintenance. Blogs must be free as open source.A blog is a platform where you can share your thoughts with the world. You can create inspirational blogs, educational blogs to help people gain some knowledge, or blogs that helps people in random everyday queries. 
He believes that blogging has become an integral part of today's society. People now use blogs for various reasons. He personally has a tumblr blog just to show his different interests. Others have very complex blogs that display their journeys and hardships, which is a very amazing thing. People have the opportunities to go on trips out of the country and are able to blog about their experiences to show others everything that is going on. Blogging has allowed people and organizations to reach more.Keeping that in mind, that blogging is evolving to be a mixture of content. In the past, Rahul solely wrote and never considered other formats. Fast forward to today and his content often includes a bit or episode of a podcast he recorded that fits what he is writing. He is giving the visitor the ability to choose one or the other.

The future of blogging is going to be interesting. People's attention spans are so small that reading is becoming a thing of the past. He also added his opinion that there will be others that will say that's not true. He loves to write, but often time's people prefer audio and even more so, video.

\section{Conclusion}

\subsection{Introduction}

Currently, many professionals are suggesting that blogs have tremendous potential as tools for online communication and for reaching diverse publics. Interestingly, however, scholars have been saying the same thing about the Internet for almost 10 years and most organizations have not figured out how to use their Web sites well except to sell things.

Interest in blogs and blogging has increased dramatically in recent years. Weblogs or blogs can be described as a form of personal, easy-to-manage Web sites with content presented in reverse chronological order. Bloggers are also frequently described as influential agenda setters. For instance, blogs have been found to have influence on media coverage of politics as well as facilitating communication among individuals and organizations. It follows from these observations that the blog as a form of mediated human expression and blogging as a human activity is of interest to academics from a variety of scientific disciplines. Although research projects interested in various aspects of blogs and blogging are on the rise, few articles have looked at blog research in a cumulative manner. As far as we know, no major review of methodologies, research topics and disciplinary perspectives in blog research seems to have been undertaken.

\subsection{Statement of Problem and Methodology}

This study investigates the impact of blogging as a public relation tool, whether public relation professionals and organisations are developing the use of blogs to communicate and enhance brand visibility. The method of data collection was Interviewing method in which 3 public relation professionals and 1 blogger were interviewed to examine the use of blogs by these professionals. The results of the study reveal that gradually PR practitioners are developing the use of blogs to grant coverage and build relations with other organisations and companies. It also states that blogs can used as an interactive medium between an organisation and the mass audience.

\subsection{Summary of the results}

Ultimately I believe that the jury is still out on blogging. A lot more scholarly research needs to be conducted before most organizations start blogging. Public relations professionals should not get trampled by the blogging stampede until scholars, researchers, and especially professionals actually understand them better. A blog will only be useful to an organization if it has someone to maintain it, someone trained in effective dialogic communication, and someone who has the trust of individuals and publics. Posting anonymously to blogs is not a viable option for any organization nor are attempts to manipulate blog audience members with self-serving propaganda or thinly disguised news releases. Blogs are currently great research tools, but scholars need to critically examine blogs and understand a lot more about how blogs function as persuasive/informative tools and how they fit in with organizational initiatives before jumping on the blog fleeting trend.

Based on these findings, public relations practitioners would benefit from reaching and engaging bloggers by specifically highlighting the entertainment and enjoyment aspect of their communication messages. Alternatively, they should use message delivery techniques that stress entertainment or amusement, such as a creative video or games rather than a written news release or statement. Addressing bloggers' need for belonging - the social aspect of using blogs - public relations practitioners should communicate to bloggers messages that emphasize their role as members of a particular community with unique interests also shared by the client. 
The blogosphere is a viable arena for public relations practitioners to extend their communications reach. Therefore, it is important to understand the motivations and traits of bloggers. Thus, public relations practitioners have more latitude in the way they manage relationships with bloggers and how they approach them, and more importantly, they should take into account the gratification bloggers seek to fulfil from the medium.

The results of this research show that although most public relations executives in this study understood the importance and continue use of blogging, they still have many unanswered questions. Organizations and public relation professionals are using blogs to "to engage in important conversations" and to enhance understanding of markets, customers, competitors, and employees. On the other hand, some organizations have tried to put control into social media by instituting organizational social media policies. Overall, blogging was seen as a cost effective way to receive greater reach for research and timely targeted dialogue.

\subsection{Recommendations}

This study explored the opinions of communication and public relations executives to determine their perceptions of blogging and its impact in today's marketplace. By better understanding the importance of blogs is implemented in organizations along with identifying the challenges and unanswered questions, the field of public relations can work towards improvement to gain or maintain a stronger hold on incorporating social media functions strategically and appropriately in organizations. Companies must be prepared to efficiently navigate through the ever changing landscape of social media tools as each day brings new forms of social media. Thus, an increasing number of public relations practitioners find opportunities in the blogosphere; blogs have emerged as a new venue for public relations.

Innovation in content in the past has been centred on distribution, not content, people moved from books to blogs because they were easier and faster to access, and that same reason drove people to move into social media, which gave users an easier way to distribute their thoughts. The downside to social media however, is that it's becoming noisy, hence, your content is being distributed alongside memes, links, and videos, this brought back the need for a social network that doesn't compromise on quality, and that's exactly the future of blogging, a blogging platform that is both social in distribution, and qualitative in context.

\section{Bibliography}

[1] Albrycht, E. (2004). Turning blogs into useful communication tools.

[2] AO Larsson, S. H. (2011). Blogs and blogging: Current trends and future directions. First Monday.

[3] Arther, J. (2014). Corporate blogs as a public relation tool.

[4] aryan. (2014). bh hvbh.

[5] CC Shen, J. C. (2009). The effect of community identification on attitude and intention toward a blogging community. Internet Research.

[6] Chauhan, D. P. (2014). Role of corporate blogs in branding.

[7] Chung, L. P. (2013). The blogospehere and public relations investigating practitioners' roles and blog use.

[8] DK Wright, M. H. (2008). How blogs and social media are changing public relations and the way it is practiced. Public relations journal.

[9] Duke, S. (2008). Educating public relations students to enter the blogosphere: Results of a Delphi study. Journalism \& Mass Communication Educator.

[10] Gleeson, B. (2013). How blogging changed the PR game.

[11] JA Ledingham, S. B. (2000). Public relations as relationship management: A relational approach to the study and practice of public relations.

[12] James, R. F. (2013). Why are PR agencies blogging? An exploratory study of the blogging practices of public relation agencies.

[13] Kang, M. (2009). Measuring social media credibility: A study on a Measure of Blog Credibility.

[14] Kent, M. L. (2006). Turning blogs into useful communication tools. .

[15] Kent, M. L. (2008). Using social media dialogically: public relation's role in reviving democracy.

[16] Ki, E.-J. (2012). The status of online public relations research: An analysis of published articles in 1992-2009. Journal of Public Relations Research.

[17] L Efimova, J. G. (2007). Crossing boundaries: A case study of employee blogging. 
[18] Macnamara, J. (2010). Public relations and the social: How practitioners are using, or abusing, social media. Asia Pacific Public Relations Journal.

[19] mishra, n. (2012). blogjihndfjndfijgn.

[20] N Eyrich, M. P. (2008). PR practitioners' use of social media tools and communication technology. Public relations review.

[21] Ojala, M. (2005). Blogging: For knowledge sharing, management and dissemination. Business information review.

[22] R Nacht, P. C. (2009). Realty Blogging Build Your Brand and OutsmartYour Competition. Retrieved from citeulike.org.

[23] T Kelleher, B. M. (2006). Organizational blogs and the human voice: Relational strategies and relational outcomes. Journal of Computer-Mediated.

[24] Wallace wood, r. b. (2011). Blogs and business; opportunities and headaches.

[25] Wright, D. K. (2007). Examining the increasing impact of social media on public relations practice. 